\title{
Complex Responsive Processes: An Alternative Interpretation of Knowledge, Knowing, and Understanding
}

\author{
DARREN STANLEY \\ University of Windsor (Canada)
}

This paper offers as an alternative theoretical perspective to the growing collection of commentaries on and studies of certain complex dynamical phenomena-human knowledge and knowing. Specifically, this is an introduction to another complexity-related theoretical framework known as "complex responsive processes" (CRP). CRP draws upon certain conceptual ideas from the complexity sciences as a source domain for analogies with particular characteristics of human interaction. The central concern is for how individual and collective identities arise, how such identities are related, and how they change. In this paper, an overview of certain key conceptual ideas from the complexity sciences in relation to CRP will be reviewed to situate CRP on the larger theoretical landscape of complex dynamical phenomena. In the end, this paper will examine some implications for such a framework on the ways in which certain aspects of human knowledge and knowing might relate to contexts of pedagogy: in particular, this paper examines the place of knowledge, knowing, and understanding in terms of the CRP structure of gesture-and-response or "effect" as opposed to "affect." 
... concepts such as 'individual' and 'society' do not relate to two objects separately but to two different yet inseparable aspects of the same human beings.... Both have the character of processes, and there is not the slightest necessity, informing theories of human beings, to abstract from this process character.

- Norbert Elias

Essentially, the individual is understood to be social to the core because the processes of mind are the same as social processes.

- Ralph Stacey

\section{Introduction}

This paper offers as an alternative theoretical perspective to the growing collection of commentaries on and studies of certain complex dynamical phenomena-human knowledge and knowing-with an introduction to another complexity-related theoretical framework known as "complex responsive processes" (CRP). Briefly put, a CRP perspective draws upon certain conceptual ideas from the complexity sciences as a source domain for analogies with particular characteristics of human interaction: that is, the characteristics of consciousness and self-consciousness which are understood to emerge in social processes of communicative interaction, processes of relating, and evaluative choice (Stacey and Griffin 2005). Framed as such, a particular way of thinking about organizational life presents itself that focuses attention on how members of an organization might cope with uncertainty and the unknown while these same individuals simultaneously co-create their collective futures together on an on-going basis. In other words, the central concern is for how individual and collective identities arise, how such identities are related, and how they change (Stacey 2003).

As complexity scholar and group therapist, Ralph Stacey, suggests in his book Complexity and Group Processes (2003):

The increasing intricacies of interdependence between people in modem life make it more important than ever to understand processes of human relating.

Stacey suggests that many human beings with a westernized perspective have a tendency to base an understanding of human beings (as individuals and groups) on an abstraction that marks a fundamental distinction and separation between the individual and the collective. As a response to this kind of prying apart of living phenomena, Stacey and his colleagues at the Complexity and Management Centre of the University of Hertfordshire have crafted an alternative way to understand human knowledge, knowing, and interaction based on social processes of relating where human beings, individually and collectively, co-emerge together. That is, the individual and the collective are believed to co-emerge from the same social processes that give rise to both the phenomena of individual minds and social relationships.

The theoretical underpinnings behind CRP have emerged from, and fit within, a

particular historical context of a few decades of a certain collection of conceptual ideas 
and diverse theoretical frameworks pertaining to the dynamics, conditions, and forms of various complex phenomena. In this paper, an overview of certain key conceptual ideas from the complexity sciences in relation to CRP will be reviewed to situate CRP on the larger theoretical landscape of complex dynamical phenomena, whereupon an outline of Stacey's theory of CRP will be described. In the end, this paper examines some implications for a CRP framework on the ways in which certain aspects of human knowledge and knowing might relate to contexts of pedagogy: while there are many aspects that could be examined, this paper considers the role of the teacher in terms of "effect" as opposed to "affect" - a reflection of Stacey's gesture-response structure.

\section{On the Resonance of Certain Theories of Complex Phenomena and CRP}

It might be tempting to suggest that many of today's complexity-related ideas arose during more recent times. Much of Norbert Elias' (1991) work from the 1930s and 1940s on social processes and personality structures, however, resonate with, and find support in, particular key ideas more recently associated with the complexity sciences, especially the notions of "self-organization" and "emergence." Indeed, as Stacey (2003) points out, Elias' ideas appeared "well before the appearance of the new sciences of nonlinear dynamics, which include far-from-equilibrium thermodynamics, mathematical chaos theory and theories of complex adaptive systems." The point, here, is not so much to give a certain precedence or priority to Elias' work and ideas, but rather to show that the developments in the complexity sciences do, in fact, support what he was arguing for as "the ubiquitous presence in nature of the unpredictable order in disorder through processes of spontaneous self-organization" (Ibid.).

Many of the concepts derived from, or associated with, the complexity sciences can be found in a number of different domains, especially during the past couple decades. These domains include the study of physiological subsystems (Bassingthwaighte, Liebovitch, and West 1994), cognition (Capra 2002), organizations and the management of organizations like the workplace (Axelrod and Cohen 1999; Guastello 1995), the social sciences (Byrne 1998), the arts (Briggs 1992), cultural complexity (Hannerz 1992), the development and evolution of urban and suburban centers (Jacobs 1969), and ecology (Ball 1999). This list can be extended quite easily given that complexity thinking, suffice to say, has more or less been used in recent times to address many different scales of complex organizational phenomena in a transdisciplinary fashion. To be sure, the complexity sciences are concerned with the apparently disordered and sometimes turbulent nature of certain systems in the natural and virtual worlds. As Waldrop (1992) points out, the science of complexity, as a study of phenomena at the edge of order and chaos, seems to "defy all the conventional categories," touching upon phenomena like stock market crashes, the evolution of species and ecosystems, the collapse of countries and economic markets, and the mind, just to name a few.

Complexity science also has made some headway into education and educational research, albeit slowly, as evidenced by the number of important texts that are to be found (Davis \& Sumara 2006; Davis, Sumara, \& Luce-Kapler 2000; Doll 1993; Doll, 
Fleener, St. Julien, \& Trueit 2005; Morrison 2002). As Davis and Sumara (2006) point out, complexity prompts a kind of "level-jumping between and among different layers of organization" orienting one's attention to "other dynamic, co-implicated, and integrated levels, including the neurological, the experiential, the contextual $/ \mathrm{material}$, the symbolic, the cultural, and the ecological." It is fitting, as such, that complexity science would have something to say about the many aspects of teaching and learning, but even more generally to the large complex systemic picture of education. Hailed as a "new science" by such popularizing texts as Gleick's Chaos: Making a New Science and Lewin's Complexity: Life at the Edge of Chaos, the "field" appears as a coherent collection of theoretical strands (like chaos theory, the theory of dissipative structures, and complex adaptive systems), emphasizing the complexity and diversity of the field itself. Certainly, a number of key conceptual elements (for example, nonlinearity, selforganization, and emergence) lie at the heart of these and other theories that concern the dynamism and dynamics of complex phenomena-products and processes.

Conceptually speaking, deterministic laws and rules are said to direct the course of certain kinds of systemic phenomena and the patterned and patterning possibilities thereof. In the case of chaos theory, deterministic nonlinear equations are said to drive the phenomenon of interest where every functional or operationalized output is also an input: recursivity or reiteration is said to drive the system onward. While long-term predictability may not be possible, a particular pattern can be known for a given range of a control parameter where an "implicit order" can be found through the on-going iterations of the system (Stacey 2003). As the parameter changes, however, the overall pattern of the attractor can change qualitatively at certain critical parametric values. That is, as various textual references describe a phenomenon known as the "butterfly effect" which suggests a "sensitivity to initial conditions," a change in the parametric values (and not so much the independent variables) of a system can change the overall attractor (Kelso 1995). In any case, the overall patterns may be described as stable, unstable or strange attractors (depending upon the parametric control value). What appears in the end, however, is a kind of image depicted as a spatialized pattern abstracted from time or as some rhythmic pattern when viewed as a temporal process (Stacey 2001). To be sure, chaos theory is concerned with the overall behavioral pattern of the attractor set as a whole where a pattern can be changed from the "outside" of the system by adjusting a control parameter.

Furthermore, Stacey (2003) notes that chaos theory cannot be applied so simply to human activities that are, by and large, not deterministic. Of course, some people say that certain human behavior may appear, if only at certain times, to be quite predictable to them as observers of human behavior, although long-term predictability is not possible. As a source domain of metaphors for human action, chaos theory reminds us that unpredictability challenges many well-established views of human cognition. Naturally, chaos theory, which addresses phenomena that are paradoxically stable and unstable all-at-once, is not the only theoretical framework to do so. In fact, Prigogine's theory of dissipative structures also addresses dynamical phenomena of a turbulent nature (Prigogine and Stengers 1997; Nicolis and Prigogine 1989). Again, Stacey (2003) 
also objects to the simple application of Prigogine's theory of dissipative structures, although there is a striking resonance with Elias' work. The theory of dissipative structures also makes the claim that particular kinds of dynamical phenomena are, paradoxically, simultaneously stable and unstable phenomena. As Stacey (2003) points out, Pigogine's ideas on "unknowable futures emerging in local interactions in the present" are "essentially the same" as Elias' ideas on "the transformative process of social evolution".

As such, Prigogine takes not the individual entity as the fundamental unit, but the collective where variability in the actions of the individuals can prompt change in the larger collective through the amplification of those differences. In this manner, the larger collective self-organizes, and the variable fluctuations in local interactions prompt the collective to move into different patterns or symmetry breaks at points of bifurcation. In a system of locally improvising entities, there needs to be a certain measure of diversity in those entities and a capacity for individuals, as well as the larger organization, to adapt across the many scales of organization in the environment. This characteristic of local diversity in interaction resonates with Stacey's interpretation of Elias' work on "social processes that form and are formed by individuals". Under the on-going transformation of the whole and the parts, both the individuals and the collective whole change through a process in time that affects the individuals and the whole in the local interactions of the improvising parts. This phenomenon can best be thought of as paradoxical where a "both-and" mindset sees how the parts influence the whole and the whole, as well, influences the evolution of the parts.

As a framework for the modeling of particular kinds of collectives, complex adaptive systems (CAS) involve the study of (usually) large collections of agents that act according to their own rules of local interaction. As with the phenomenon of dissipative structures, no single entity or subset of entities in the collective can determine the behavior of the larger whole. As Stacey (2003) rightly points out, no agent can stand "outside" the system to direct the system as each and every agent is already a part of the system. Given the local responsiveness of each agent in the system, the unfolding of the systemic whole occurs without a blueprint and authority figure. Such systems have the capacity for a diverse range of possible patterns arising from certain conditions and principles such as redundancy, variability, local interaction, and organized randomness (Johnson 2001).

Still, in many examples of CAS (most notably computer simulations), the agents in the system do not adapt, although the larger "system" might. Unlike dissipative structures, these agents tend to follow the same (small set of) rules of interaction with a uniformity to and in their interactions. What emerges, therefore, is the result of local interactions, rather than a diversity in the agents. That is, in systems like computer models, the agents tend to be homogeneous in nature where their virtually-reified "bodies" are identical to one another. As such, the possibility for moving into other kinds of patterns remains improbable, limiting the collective to a few already-known or knowable patterns. 
Of course, not all CAS function in this fashion. In some cases, the agents are not homogeneous and, therefore, open up the possibility for new attractor sets. Like dissipative structures, some CAS can persist in a coherent and intrinsic fashion through a spontaneous emergence of transformation and continuity. The difficulty that Stacey (2003) has with CAS is that it becomes too easy for one to "focus attention on the 'system' and lose sight of the process of interaction". To do so, one risks reifying the system, forgetting that while coherence may "hold" the system together, it cannot be experienced as a cohesive whole but only as on-going patterns of relating.

\section{CRP as a Framework for Knowing}

The notion of CRP is one that evolved during the 1990s through the on-going efforts of Ralph Stacey (2001, 2003) and his colleagues (Shaw 2002; Stacey and Griffin 2005). CRP, as an intellectual framework to understand human action, emerged as a response to particular difficulties they found from applying certain concepts drawn directly from the underlying conceptual ideas for complex adaptive systems. Stacey's arguments speak out against the direct application of concepts drawn from CAS to understand human action and life in organizations, calling for a need to incorporate into one's understanding of human action and organizations considerations for human consciousness, self-consciousness, the mind, self and society as well as power dynamics and identity formation (Stacey and Griffin 2005).

Stacey's need to understand human action and life in social organizations differently stems from a view that organizational phenomena are fundamentally temporal processes rather than spatial phenomena: such "bodies" are fundamental to a "system" wherein local interacting bodies give rise to other coherent bodies at other scales of organization. Rather, the theory of CRP is concerned with the notion of "temporally iterated interaction" as the fundamental aspect of human reality where the concept of a "whole" as a spatialized concept is an "imaginative construct arising in that interaction" (Stacey and Griffin 2005). Put differently, the spatialized nature of bodies, a fundamental feature of CAS, cannot be an aspect of certain phenomena like the mind, society, and social organizations. The reification of such phenomena demands the postulation of a boundary and, hence, the notions of "inside" and "outside," which is problematic. Thus, the notion of "embedded bodies," a notion frequently alluded to under a CAS-oriented framework, is called into question - at least as far as such notions as the mind, society, and social organizations are concerned.

Given that CRP are understood as temporal processes, one can articulate all at once a theory of self and the social aspect of human beings since all human interactions are simultaneously interactions with others and one's self. Drawing upon the work of Norbert Elias, Stacey argues that his theory of CRP offers a view of two (apparently) different phenomena manifest through the same processes, the singular and plural "forms" of relating with one's self and others. Given that any interaction can only give rise to further interactions, an interaction produces nothing-nothing above nor below, neither inside nor out. As Stacey (2003) writes: 
Interaction produces only further interaction and is its own reflexive, self-referential cause. There is only process, no system at all. In fact there is no inside and outside. There is no 'internal' world and there is no social system. (p. 5)

Put differently, Stacey says:

In the spatial sense interaction is a process producing a system inside and a system outside as the "wholes" of mind and society. In the temporal sense, however, process is not producing anything other than itself. (p. 7)

Interactions are essentially actions between human bodies-even with one's self-where each action gives rise to a structure of gestures and responses, a structure which is fundamentally communicative since each gesture gives rise to a response and each response gives rise to a gesture. Through our uniquely evolved biological structure (especially our capacity for consciousness and self-consciousness awareness), we have developed a significant ability to evoke in others similar responses that we have for ourselves. These shared responses show how as human beings we can communicate in "significant symbols": Through this sense of "shared" understanding, therefore, we have the ability as individuals to act in ways that reflect our own expectations of how others might respond.

Historically, in terms of Western thought, the distinction between the individual and the collective has suggested that the mind is inside a person and that those things described as social are outside a person in the form of a system. As such, individuals are said to be "social" because "they represent the social outside in the inside of their minds" (Stacey 2003). The mind and the social collective, however, are patterns that arise from the activities of human bodies. Thus, paradoxically speaking, the mind shapes and is shaped by the actions of other human beings: "Individuals," Stacey writes, "are then thought of as social not because of representations of social relations in their minds but because the processes of mind are the same processes as social relating" . It is important, however, to note that this particular stance does not diminish the experiences that we may have of our own individuality or our social relations with others.

As an "individual," the endless activity and chatter of my mind-the silent conversations with myself, the songs that are sung, the images that "enter" my mind, and private feelings that I experience-is not something "inside" of me, but rather the self-directed activity of my own body. As Stacey (2003) suggests, such a thought "in no way requires me to think of myself in an abstract way as having an 'internal world"' . As Stacey reminds us, following Elias' arguments, this is an illusion that has evolved over time as a result of an apparent social need to keep what we truly experience hidden from others (Elias 1994). Of course, it may not even be possible to cease talking about the mind and the social through spatial metaphors, i.e., container metaphors. Naturally, there is an extensive body of literature by cognitive linguists (see Johnson 1987; Lakoff \& Johnson 1980) who have proposed that such conceptual metaphors play an important role in our understanding of the nature of our embodied cognition. For this reason, we may continue to express our own experiences through such metaphorical structures. That said, it may not be appropriate to continue talking about and describe our 
experiences in ways that are problematic: to talk about our experiences in terms of "insides" and "outsides" is still an abstraction from our immediate interactions with others. To do so, may, in fact, suggest that we may not take our experiences seriously enough in spite of the fact that such abstractions must be significant meaningful symbols of interaction.

Shifting the ways in which we might think about what goes on and happens in the classroom are bound to affect us - as teachers and students - in ways that cannot be known in advance. In a profession that is largely understood as a body that presents knowledge as something that is a given, known and fixed, uncertainty would seem to hold no place. But, more importantly, and for the purposes of this paper, the remaining sections of this paper will give some consideration to the relationships between knowledge, knowing, and understanding within a pedagogical context.

\section{Complex Responsive Processes: \\ A Radical Understanding of Teaching and Learning?}

The question of "What is happening when one is 'learning'?" suggests a myriad of other concerns and questions. Concerned as one might be to describe a theory of cognition, one might wonder about how the mind works, the relationship between the mind and the brain, how learning unfolds, the status of knowledge, and the kinds of insights that contemporary views of learning might hold for teaching (Davis, Sumara, and LuceKapler 2000). Literally, as a "way of seeing," a theory of learning, with attending assumptions and assertions, forms the basis for all teaching. An emphasis on how one might think about what we do together in the classroom makes a great difference in practice: to think otherwise plays into a "key taken-for-granted feature of current Western thought" that envisions a gap between our "ways of thinking as theory from action as practice" (Stacey 2003). Instead, as Stacey purports, "as one thinks differently so one practices differently" (Ibid.).

Historically, the field of education bears the marks and traces of a number of different theoretical frames that described the phenomenon called "learning." Many of my own experiences in school as a student would allude to a range of "complicated" notions: learning was mechanical, machine-like, linear, goal-oriented, and directed towards the need to be efficient. Of course, these descriptors are essentially those described in the work of Davis and colleagues (2008). As many readers of this journal will attest, these terms and images are compared and contrasted with other more "complex" ones: thus, references to biological metaphors, feedback loops, growth, and sufficiency-oriented are used. The difference is quickly summed up in terms of theories of correspondence or complexity ${ }^{1}$.

\footnotetext{
${ }^{1}$ In "between" these two theoretical perspectives on learning, Davis et al. refer to "coherence theories" as a set of alternatives to two correspondence theories: mentalism and behaviourism. This set of alternatives varies with the specific attention and interest of a theorist who may focus on the individual, social collectives, various cultures, and the environment. But, more generally, they reject various false dualisms, e.g., body/mind, self/other, individual/other, knower/knowledge, and human/non-human.
} 
This paper does not deny the idea that education is a "transphenomenon," referring to the term as used by Davis (2005). It would be difficult to argue that a range of attentions to different scales of phenomena is not pertinent to the project of schooling and education. To be clear, however, it is the extent to which particular principles form the basis for each scale of learning: these principles-e.g., diversity, redundancy, nonlinearity, neighboring interactions, decentralized control, etc.-are addressed throughout the larger complexity literature as well as the more specific literature on education and complexity. Still, the overarching framework of complexity invokes a spatialized notion of learning - learning bodies.

This paper argues for some reconsideration to be given to phenomena like the mind, society, and organizations - one rooted in a temporalized understanding of learning as opposed to a spatialized one. The metaphor of the "body" needs to be reconsidered. As such, some consideration must be given to the notions of "knowledge," "knowing," and "understanding" as alluded to in the title of this paper in terms of the contexts of teachers, students and classroom settings. If learning and understanding, for instance, are to be understood more in terms of temporalized processes as opposed to spatialized phenomena, what thoughts or insights might arise?

First, it is important to recognize another influence on Stacey's work which can be found in the writings of George Herbert Mead, particularly Mead's 1934 work on Mind Self and Society. It is important to point this out here for Mead's notion of the "conversation of gestures." As a social act, the "gesture-and-response" structure of interaction between students or teacher-and-students constitutes meaning for all involved (in some way and even for other listeners) as every gesture by one person calls forth a gesture by another. The co-emergent meaning lies in the relational nature of the classroom every affect prompts an effect and so on. Where meaning does not rest within any "part" of the gesture-and-response structure, i.e., "within" the individual, meaning does arise as a result of interaction (that begets only further interaction) in a fashion that resonates with Maturana and Varela's $(1980,1992)$ concept of "structural determinism." As such, we might consider the classroom as a "conversation of gestures" or, as Davis and Sumara (2006) have described, as a "structurally determined" body.

Such a structural understanding of the classroom suggests a strong historical place, a place in the "historical present" which simultaneously re-constructs the future. The structure of the classroom, therefore, announces a particular sense of time that is necessarily non-linear to some degree given the nature of the healthiness of the relationships. Even more, every such structure of gesture-and-response announces a kind of symbol in some sense as a meaningful action. The significance of such a symbol would suggest and calls forth the same (or a similar) effect in she who gestures towards another. It is this self-reflexive nature with one's self that allows the teacher, therefore, to "know what to do" in terms of planning, instructing, and other forms of interaction. In other words, as Stacey (2003) writes, it is the evolution of our central nervous systems as a biological beings that has "enabled [us] to gesture to others in a manner that [is] capable forth in [ourselves] the same range of responses as in those to whom [we] are gesturing" (p. 61). 
When I plan for my classes, therefore, I am engaging in a social conversation of gestures (with myself) that I imagine happening with my own students. That is, I have the capacity to imagine the possible consequences of my gestures. To suggest that such actions were merely "planning" falls short of the simultaneous possibility for transformation in the teacher and her students. To be sure, in the realm of the social, there is also the presence of continuity as in the on-going presence of coherent thought, beliefs, and cultural patterns as they might be played on in the nature and structure of the classroom - rows of desks, blackboards, curriculum guides, direct instruction and so on. Although habits of mind and body do change in time, the social structures of the classroom that is a conversation of gestures serves as a structure which is "shared, repetitive and enduring" in its "values, beliefs, traditions, habits, routines and procedures" (Stacey 2003, p. 65).

As discussed, education bears the marks and traces of a number of different theories of learning described by Davis and his colleagues (2008) as theories of coherence and complexity. One might, however, re-cast such a distinction in terms of "affect" and "effect." The former reflects a view of learning that is apparently well-defined, caught up in notions of linear cause-and-effect relationships. The latter notion of "effect," however, resonates well with Stacey's thinking on CRP. Specifically, the communicative structure of gesture-and-response reflects the notion of "effect." To be sure, CRP is rooted in processes of self-organization and learning, in relation to how individual and collective identities arise, how such identities are related, and how they change, is more appropriately thought of in terms of the communicative structure of gesture-andresponse. Stacey might, in fact, suggest that we are every bit alike as we are differentwe are complex beings, after all. But if one were to take one's experiences seriously, one would see that the individual is social through and through, arising through the same on-going patterns of human interaction. To use two terms used by Davis (as well as others), we might move towards an understanding of teaching as "prompting" or "occasioning" learning.

When I understand something, therefore, it arises from some interaction that calls forth some meaningful symbol-even if only for myself as when I prepare for my weekly classes at the faculty. Such a prompt calls forth the possibility of an apparent paradox of simultaneous continuity and transformation. Knowing, therefore, cannot be a case of "knowing that," but possible knowledge arising in interaction. Knowledge is never an absolute, neither fixed nor given. It is emergent possibility - the "effects" of a gesture-and-response social structure of interactivity rather than mere "affects" as in a transactional framework - arising from the social interactions of our embodied minds in relation to ourselves and one another.

\section{References}

Axelrod, R. M., and M. D. Cohen. 1999. Harnessing complexity: Organizational implications of a scientific frontier. New York: Free Press.

Ball, P. 1999. The self-made tapestry: Pattern formation in nature. Oxford, England: Oxford University Press.

Bassingthwaighte, J. B., L. S. Liebovitch, and B. J. West. 1994. Fractal physiology. New York: Oxford University Press. 
Briggs, J. 1992. Fractals: The patterns of chaos: A new aesthetic of art, science, and nature. New York: Simon \& Schuster.

Byrne, D. 1998. Complexity theory and the social sciences: An introduction. New York: Routledge.

Capra, F. 2002. The hidden connections: Integrating the hidden connections among the biological, cognitive, and social dimensions of life. 1st ed. New York: Doubleday.

Davis, B. 2005. Complexity and education: Some vital simultaneities. Paper read at Proceedings of the 2005 Complexity Science and Educational Research Conference, November 20-22, 2005, at Loranger, LA.

Davis, B., and D. J. Sumara. 2006. Complexity and education: Inquiries into learning, teaching, and research. Mahwah, NJ: Lawrence Erlbaum Associates.

Davis, B., D. J. Sumara, and R. Luce-Kapler. 2000. Engaging minds: Learning and teaching in a complex world. Mahwah, NJ: Lawrence Erlbaum Associates.

- - - 2008. Engaging minds: Changing teaching in complex times. 2nd ed. New York: Routledge.

Elias, N. 1991. The society of individuals. Cambridge, MA: Blackwell.

- - . 1994. The civilizing process. Cambridge, MA: Blackwell.

Guastello, S. J. 1995. Chaos, catastrophe, and human affairs: Applications of nonlinear dynamics to work, organizations, and social evolution. Mahwah, NJ: Lawrence Erlbaum Associates, Inc.

Hannerz, U. 1992. Cultural complexity: Studies in the social organization of meaning. New York: Columbia University Press.

Jacobs, J. 1969. The death and life of great American cities. New York: Modern Library.

Johnson, S. 2001. Emergence: The connected lives of ants, brains, cities, and software. New York: Scribner.

Kelso, J. A. S. 1995. Dynamic patterns: The self-organization of brain and behavior. Cambridge, MA: MIT Press.

Nicolis, G., and I. Prigogine. 1989. Exploring complexity: An introduction. New York: W.H. Freeman and Company.

Prigogine, I., and I. Stengers. 1997. The end of certainty: Time, chaos, and the new laws of nature. 1st Free Press ed. New York: Free Press.

Shaw, P. 2002. Changing conversations in organizations: A complexity approach to change, Complexity and emergence in organizations. London and New York: Routledge.

Stacey, R. D. 2001. Complex responsive processes in organizations: Learning and knowledge creation. London and New York: Routledge.

- - - 2003. Complexity and group processes: A radically social understanding of individuals. New York: BrunnerRoutledge.

Stacey, R. D., and D. Griffin. 2005. A complexity perspective on researching organizations: Taking experience seriously. New York: Routledge.

Waldrop, M. M. 1992. Complexity: The emerging science at the edge of order and chaos. New York: Simon and Schuster.

\section{About the Author}

Darren Stanley is Assistant Professor of Elementary Education (Mathematics) in the Faculty of Education at the University of Windsor in Windsor, Ontario. He received his doctorate form the University of Alberta, and his research interests include the study of complex phenomena as a paradigm for understanding and framing aspects of health and healthy learning organizations, including healthy schools. Additionally, he is interested in the circulation of lived phenomena with complexity frameworks. As a teacher educator in the faculty's pre-service education program, he is interested in the ways in which pre-service teachers enact various pedagogical stances to mathematical knowledge and understanding. (E-mail address: dstanley@uwindsor.ca)

(C) Copyright 2009. The author, DARREN STANLEY, assigns to the University of Alberta and other educational and non-profit institutions a non-exclusive license to use this document for personal use and in courses of instruction provided that the article is used in full and this copyright statement is reproduced. The author also grants a non-exclusive license to the University of Alberta to publish this document in full on the World Wide Web, and for the document to be published on mirrors on the World Wide Web. Any other usage is prohibited without the express permission of the authors. 